\title{
PROCEDIMENTOS DE CONTROLE DO VOLUME DE MADEIRA ESTIMADO E COLHIDO EM UM PLANTIO DE Pinus spp. NO PARANÁ
}

\author{
CONTROL PROCEDURES OF VOLUME OF ESTIMATED AND HARVESTED WOOD IN A \\ PLANTATION OF Pinus spp. IN PARANÁ STATE
}

\author{
Silvane Vatraz ${ }^{1}$ Fabricio Quadros Borges ${ }^{2}$
}

\section{RESUMO}

O objetivo desta investigação foi aperfeiçoar os procedimentos operacionais de controle entre o volume de madeira estimado pelo inventário florestal e o volume efetivamente colhido, de modo a reduzir as inconsistências no planejamento florestal praticado em um empreendimento florestal com plantio de Pinus spp. no Paraná. Nesse sentido, foram utilizadas as ferramentas de qualidade: Brainstorming e o Ciclo PDCA, através de uma investigação de caráter exploratório junto ao empreendimento estudado. $\mathrm{O}$ estudo apresentou uma inconsistência volumétrica inicial de - 24,73\% entre o volume estimado pelo inventário e o efetivamente colhido. Esta inconsistência foi composta de falhas operacionais nas atividades de Inventário Florestal $(+13,84 \%)$, Colheita Florestal $(+15,62 \%)$ e de Expedição de Madeira $(-3,08 \%)$. As aplicações das ferramentas de qualidade auxiliaram na identificação da inconsistência, assim como na revelação de falhas operacionais, o que sugeriu algumas rotinas de acompanhamento e de checagem de cada uma das atividades envolvidas no gerenciamento operacional florestal.

Palavras-chave: Pinus spp.; ferramentas da qualidade; inventário florestal.

\begin{abstract}
The objective of this research was to improve the operating procedures of control of the volume of timber estimated by the forest inventory and the effectively harvested volume in order to reduce inconsistencies in the forest planning practiced in a forestry plantation of Pinus spp. in Paraná state. Accordingly, we used the tools of quality: storming and PDCA Cycle through an exploratory research project to study together. The study showed an inconsistency initial volume $-24,73 \%$ of the volume estimated by the inventory and the effectively harvested wood. This inconsistency was composed of operational failures in the activities of Forest Inventory $(+13,84 \%)$, Forest Harvesting $(+15,62 \%)$ and Expedition Wood $(-3,08 \%)$. The application of quality tools helped in the identification of inconsistency, as well as the revelation of operational failures, which suggested some routine monitoring and checking each of the activities involved in managing operational forestry.
\end{abstract}

Keywords: Pinus spp.; quality tools; forest inventory.

\section{INTRODUÇÃO}

As empresas de base florestal possuem, como um dos seus principais objetivos, a obtenção de algum tipo de retorno econômico dos plantios florestais que realizam. As limitações impostas pela qualidade da matéria-prima, preços, mercados, localização geográfica e transporte, dentre outros, passaram a ser fatores fundamentais na tomada de decisões (ARCE, 1997).

Com a globalização da economia, o acirramento da concorrência entre as empresas de base florestal passou a existir. Cada qual passa a se preocupar e a tomar decisões no sentido de buscar

1 Engenheira Florestal, Doutoranda em Ciências Florestais, Universidade Federal Rural da Amazônia, Av. Perimetral, 2501, CEP 66077-830, Belém (PA), Brasil.vatraz@yahoo.com.br

2 Economista e Administrador, Dr., Pós-doutor em Gestão de Tecnologia, Professor do Quadro Permanente - Gestão da Qualidade, Instituto Federal do Pará, Av. Almirante Barroso, 1155, CEP 66093-020, Belém (PA). Brasil. doctorborges@bol.com.br 
o máximo de aproveitamento da matéria-prima disponível e otimização do processo produtivo. Os objetivos das empresas passam a ser redução no custo de produção e melhoria da qualidade do produto, fatores estes, decisivos na competitividade das empresas no mercado (COLETTI, 2010).

Dentre os desafios apresentados, destacase o gerenciamento, notadamente o ambiente pertinente ao planejamento e controle do uso de produtos florestais madeireiros. Este ambiente compreende aspectos de gestão relacionados à definição de metas a partir das limitações e das potencialidades disponíveis em uma determinada unidade de manejo.

O planejamento coerente da escolha da unidade de manejo a ser colhida pelos gestores da empresa deve enfocar a produção da floresta, bem como as condições de mercado para os produtos a serem gerados nesta área, a fim de otimizar as operações subsequentes, como a colheita florestal. Por isso a importância da informação correta da estimativa volumétrica, pois a mesma se estiver incorreta, pode influenciar de forma negativa os resultados gerenciais da empresa. Assim como os procedimentos de operação de colheita e de expedição de madeira também devem fazer parte da intenção de fornecimento de elementos estrategicamente necessários ao planejamento e controle eficiente do uso da matéria-prima florestal.

De acordo com Jurane Gryna (1991), um programa de gerenciamento, adequadamente elaborado e executado, deve proporcionar melhorias significativas em termos de eficiência, segurança, controle de qualidade e desempenho. Algumas ferramentas de qualidade são essenciais para a boa execução do programa, conforme descrito por Bonduelle (2007): o Brainstorming ou tempestade cerebral é uma ferramenta que auxilia as pessoas a produzirem ideias para a resolução de um problema; ciclo PDCA é uma ferramenta de gestão que pode ser utilizada como auxílio no diagnóstico, análise e prognóstico de problemas organizacionais, sendo de importância fundamental para a solução de problemas.

Esta investigação aplicou as ferramentas de qualidade acima descritas em um estudo de caso de caráter exploratório junto a um empreendimento florestal com plantio de Pinus spp. localizado no Paraná. O objetivo foi o de aperfeiçoar os procedimentos operacionais de controle entre o volume de madeira estimado pelo inventário florestal e o volume efetivamente colhido, de modo a reduzir as inconsistências no planejamento florestal praticado no empreendimento analisado.

\section{MATERIAL E MÉTODOS}

\section{Caracterização do local de estudo}

A investigação possui caráter exploratório e se desenvolve junto a um plantio de Pinus spp. de 28 anos de idade, em uma área de 307,98 ha, localizado em empreendimento do segmento florestal, no município de Doutor Ulysses, Estado do Paraná. O empreendimento foi adquirido em fase adulta, onde um desbaste já havia sido realizado de forma sistemática e seletiva, aproximadamente aos 16 anos.

O inventário praticado pela empresa detentora do empreendimento une os conceitos de inventário florestal contínuo com inventário florestal pré-corte em uma metodologia que atende tanto a demanda de informações para planejamento estratégico da empresa como na geração de resultados que podem ser prontamente empregados para fins mais operacionais. A técnica de amostragem é sistemática com parcelas circulares fixas $\left(500 \mathrm{~m}^{2}\right)$, dispostas em um grid de $200 \mathrm{~m}$ x $200 \mathrm{~m}$, onde a fração de amostragem é de $1,25 \%$, ou seja, uma parcela para cada 4 hectares.

\section{Ferramentas de qualidade aplicadas}

Brainstorming: Esta técnica foi utilizada com o objetivo de definir o problema e suas possíveis soluções, através da geração de ideias em consulta com as partes envolvidas. Todas as informações que pudessem relacionar-se com o problema foram coletadas, avaliadas e então selecionadas as melhores ideias.

Após a aplicação do Brainstorming, com o objetivo de direcionar a discussão, organizando-a em um plano de ação, foi empregado o ciclo PDCA. Poucos instrumentos se mostram tão efetivos para a busca do aperfeiçoamento quanto esse método de melhoria contínua, tendo em vista que ele conduz a ações sistemáticas que agilizam a obtenção de melhores resultados, com a finalidade de garantir a sobrevivência e o crescimento das organizações (PACHECO et al., 2011).

Ciclo PDCA: Ainclusão da técnica objetivou melhorar e manter a qualidade dos processos de controle dentro do empreendimento analisado. De acordo com Juran (1998), o ciclo PDCA é realizado 
na seguinte sequência: planejar, executar, verificar e atuar corretivamente. No entanto, segundo Equipe Grifo (1998), o PDCA pode ser resumido somente em três fases, as quais serão utilizadas nesse artigo. A primeira fase corresponde a "Preparação", onde se identificam e se relacionam os problemas e é realizado o planejamento das ações que reverterão esses problemas; a segunda fase é a "Implantação", onde se relacionam com as etapas de execução e de verificação de acordo com Juran (1998) e a próxima fase, a "Manutenção", na qual ocorre a consolidação dos ganhos conforme a fase anterior garantindo o prosseguimento, com sucesso, do programa.

\section{RESULTADOS E DISCUSSÃO}

O Brainstorming realizado com os gestores da empresa com o intuito de averiguar as diferenças volumétricas entre os valores estimados pelo inventário florestal e o efetivamente colhido, chegou à conclusão de que as áreas envolvidas no processo deveriam ser investigadas, a fim de detectar possíveis falhas operacionais que estão influenciando o resultado final. As áreas indicadas para verificação compreendem: Inventário Florestal e Cartografia (Planejamento), Colheita Florestal e Expedição da Madeira.

Esse método proporciona uma visão genérica do problema, fato importante para se iniciar sua análise, porém, para a busca da causa de um efeito indesejado, é necessária a aplicação de ferramentas mais específicas para a análise, como o PDCA.

A Tabela 1 ilustra as três fases do ciclo PDCA, conforme as áreas operacionais da empresa indicadas para investigação, segundo o Brainstorming realizado.

De posse destas informações tabuladas, pode-se elaborar um plano de ação específico para cada uma das áreas investigadas, a fim de garantir a efetividade do método aplicado.

\section{Inventário Florestal e Cartografia (1)}

A determinação do volume sólido em povoamentos florestais é imprescindível para o gerenciamento florestal. Para quantificar esse volume executa-se um inventário florestal que consiste na medição de parte da população, isto é, de unidades amostrais ou parcelas, para depois extrapolar os resultados para a área total. Assim, visando planejar as operações florestais, têm-se estimativas da quantidade e da distribuição da madeira disponível (LEITE e ANDRADE, 2002).

Estimativas de volume de madeira em inventários florestais incluem erros de amostragem e erros de não amostragem. São várias as fontes deste segundo tipo de erro, dentre elas o uso de

TABELA 1: Aplicação do PDCA nas áreas a serem investigadas.

TABLE 1: Application of PDCA in the areas to be investigated.

\begin{tabular}{|c|c|c|c|}
\hline ITENS & $\begin{array}{c}\text { PREPARAÇÃO } \\
(\mathrm{P}=\text { Planejamento })\end{array}$ & $\begin{array}{l}\text { IMPLANTAÇÃO } \\
(\mathrm{D}=\text { Executar e } \\
\mathrm{C}=\text { Checar })\end{array}$ & $\begin{array}{c}\text { MANUTENÇÃO } \\
\qquad(\mathrm{A}=\text { Agir })\end{array}$ \\
\hline $\begin{array}{l}1 \text { - INVENTÁRIO } \\
\text { FLORESTAL E } \\
\text { CARTOGRAFIA }\end{array}$ & $\begin{array}{l}\text { Identificar a informação do volume } \\
\text { estimado pelo processamento do } \\
\text { inventário florestal e revisar a } \\
\text { base cartográfica, pois a área esta } \\
\text { intimamente ligada no cálculo da } \\
\text { estimativa volumétrica }\end{array}$ & $\begin{array}{l}\text { Verificar os dados coletados em campo } \\
\text { (amostragens), os cálculos utilizados } \\
\text { nas estimativas volumétricas, como as: } \\
\text { equações hipsométricas, volumétricas } \\
\text { e seus coeficientes. Verificar todos os } \\
\text { artifícios utilizados na elaboração dos } \\
\text { mapas utilizados, bem como checar } \\
\text { em campo possíveis inconsistências } \\
\text { cartográficas }\end{array}$ & A definir \\
\hline $\begin{array}{l}2 \text { - COLHEITA } \\
\text { FLORESTAL }\end{array}$ & $\begin{array}{l}\text { Identificar possíveis desperdícios de } \\
\text { madeira comercial no processo de } \\
\text { colheita do produto }\end{array}$ & $\begin{array}{l}\text { Verificar a altura de toco remanescente } \\
\text { e resíduos adicionais em campo, bem } \\
\text { como checar o traçamento das toras em } \\
\text { seus sortimentos comerciais }\end{array}$ & A definir \\
\hline $\begin{array}{c}3 \text { - EXPEDIÇÃO DE } \\
\text { MADEIRA }\end{array}$ & $\begin{array}{l}\text { Verificar os volumes de madeira } \\
\text { expedidos e os mensurados em } \\
\text { campo }\end{array}$ & $\begin{array}{c}\text { Checar o emprego do método de } \\
\text { medição de madeira em campo } \\
\text { (tora a tora), fatores de conversão, } \\
\text { classificação de sortimentos, medição de } \\
\text { comprimentos das toras e expedição da } \\
\text { madeira }\end{array}$ & A definir \\
\hline
\end{tabular}


equações inadequadas para estimar a altura e o volume de árvores individuais (LEITE et al., 2003). Geralmente os inventários florestais realizados nas empresas de base florestal são terceirizados. Dificilmente a empresa mantém uma equipe própria para a realização desta atividade, visto sua natureza estritamente técnica e de alto custo operacional.

Nesta investigação, foram incialmente checados os resultados dos inventários realizados anteriormente nesta área, a fim de consistir os dados, conforme mostra a Tabela 2.

Os dados da tabela acima mostram que não houve mudanças significativas nos resultados dos inventários florestais realizados nesta área, no decorrer de 5 anos, portanto são consistentes.

No entanto, existe ainda a necessidade de checar estes dados das unidades amostrais coletados em campo. Tendo em vista que nesta investigação o inventário florestal foi realizado por uma empresa terceirizada, optou-se por uma auditoria através de outra empresa terceirizada, junto a algumas unidades amostrais, abrangendo diferentes características e condições de declividade do terreno. Para esta seleção de unidades amostrais, utilizaram-se os dados do inventário anterior e da ferramenta para interpolação de dados do software ArcGIS.

Observou-se que a diferença entre os dados coletados no inventário anterior e aqueles apurados pela empresa que realizou a auditoria (intervalo de 8 meses) foi muito pequena, não interferindo de forma significativa no resultado final do processamento do inventário. Considerando que o erro amostral apresentado pelo último inventário foi de $2,74 \%$ para mais ou para menos, e o resultado da auditoria realizada foi de $2,94 \%$, inferiu-se que o erro estaria apenas discretamente fora do limite aceitável.

É relevante destacar que a empresa contratada para a realização do inventário verificou as equações e os coeficientes empregados no processamento dos dados de campo e os mesmos não sofreram alterações.

A auditoria da amostragem possibilitou, portanto, concluir que os dados do inventário florestal existente para o empreendimento dispõem de confiabilidade. No entanto, não basta apenas concluir que os dados do inventário florestal estão corretos, pois é preciso ainda extrapolar o volume inventariado para a área total do empreendimento. Por isso é de grande importância realizar uma verificação da cartografia utilizada nesta extrapolação, pois estas duas informações estão intimamente interligadas.

Através do uso da base cartográfica disponível (ortofoto/2005), foi possível checar o tamanho da área, presença de clareiras e a classificação de uso do solo. Foi constatada a existência de 19,74 há de capões de área nativa no interior dos talhões de pinus. Portanto, gerando uma inconsistência na classificação do uso do solo. A área oficial do empreendimento, que era de 327,72 ha, passou a ser de 307,98 ha. Essa diferença cartográfica resultou em um aumento de $+13,84 \%$ do volume total do empreendimento, utilizandose da regra de extrapolação (MIGUEL, 2009) do volume médio/ha multiplicado pela nova área.

\section{Colheita Florestal (2)}

No empreendimento observado foi empregado o uso de dois sistemas de colheita, o semimecanizado (motosserra) e o mecanizado (Harvester). Os aspectos verificados que poderiam ser classificados como resíduos adicionais foram: a altura de tocos produzidos, presença de resíduos adicionais remanescentes na área e apontamento de

TABELA 2: Demonstrativo dos resultados dos inventários anteriores.

TABLE 2: Statement of the results of previous inventories.

\begin{tabular}{cccccccc}
\hline $\begin{array}{c}\text { Ano do } \\
\text { Inventário }\end{array}$ & Área (ha) & $\begin{array}{c}\mathrm{N}^{\mathrm{o}} \text { de } \\
\text { parcelas }\end{array}$ & Dap (cm) & $\mathrm{H}(\mathrm{m})$ & Árvores/ha & $\begin{array}{c}\text { Volume comercial } \\
\left(\mathrm{m}^{3} / \mathrm{ha}\right)\end{array}$ & $\begin{array}{c}\text { Erro amostral para vol. } \\
\text { Comercial }(\%)\end{array}$ \\
\hline 2005 & 327,58 & 82 & 24,83 & 22,18 & 875,37 & 472,46 & 3,52 \\
2006 & 327,66 & 82 & 24,94 & 23,93 & 882,44 & 591,56 & 4,40 \\
2007 & 327,42 & 89 & 26,18 & 24,92 & 886,97 & 605,62 & 2,80 \\
2008 & 327,42 & 89 & 26,92 & 24,18 & 884,62 & 618,25 & 2,92 \\
2009 & 327,39 & $153^{1}$ & 26,73 & 25,18 & 882,61 & 626,65 & 2,74 \\
\hline
\end{tabular}

${ }^{1}$ Amostragem intensificada para "Inventário Pré-corte" 
madeira comercial produzida. Ainda segundo Arce (2000), as perdas decorrentes das operações de colheita são praticamente inevitáveis, motivando, portanto, o planejamento das mesmas de modo a minimizar os efeitos negativos gerados pelo desperdício sobre os custos de produção. Segundo Foelkel (2007), conforme a qualidade da floresta, as especificações do diâmetro mínimo a corte, do equipamento empregado na colheita e das habilidades e cuidados dos operadores de máquinas, o percentual de resíduos lenhosos pode variar entre 2 a $8 \%$ do volume de madeira comercial colhido.

Um inventário de resíduos foi realizado para detectar possíveis adicionais resíduos remanescentes na área. Foram instaladas 9 parcelas de 10 x 20 m, em diferentes declividades e de sistemas de colheita (semimecanizada e mecanizada). Em termos gerais, existe uma grande variabilidade na área colhida em termos de resíduos, como mostra a Tabela 3.

O volume médio total de resíduo foi de $43,12 \mathrm{~m}^{3} / \mathrm{ha}$, correspondendo a um percentual de $6,68 \%$ em relação ao volume comercial colhido, aproximando-se discretamente do limite máximo citado por Foelkel (2007). Esse percentual traduz um aumento deste mesmo valor no volume estimado para a área, ou seja, mais $6,68 \%$ do volume comercial total do empreendimento.

A expectativa da empresa para a altura de tocos é de $15 \mathrm{~cm}$ em ambos os tipos de sistemas de colheita. $\mathrm{Na}$ amostragem realizada neste trabalho, esta medida mostrou-se dentro da média esperada, onde no sistema semimecanizado a média de altura foi de $14 \mathrm{~cm}$ e no sistema mecanizado foi de $16 \mathrm{~cm}$.

Para a averiguação de possíveis desperdícios de madeira ao longo da área colhida e de verificação do boletim de apontamento de madeira comercial produzida, foi realizado um inventário expedito. Este inventário percorreu a borda de todos os talhões colhidos, ao longo de uma faixa de aproximadamente 50 metros, anotando os resultados encontrados em uma ficha de campo. Foram observadas as toras desclassificadas, toras esquecidas e as toras consideradas velhas, ou seja, aquelas que estão armazenadas em campo por mais de 30 dias, que apresentam fungos manchadores de madeira (madeira azulada) (Tabela 4).

Nesta oportunidade, foram observados em campo, todos os materiais existentes com valor comercial que teriam sido desclassificadas ou deixadas por esquecimento em áreas de difícil acesso, consideradas agora como madeira velha.

O inventário expedito registrou quantidades significativas de madeira nova, cerca de $5.337,27 \mathrm{~m}^{3}$ $(+5,79 \%)$, que não foram mencionadas no boletim de produção até o momento, que são importantes no apontamento do estoque geral colhido. Em relação à madeira considerada como velha houve um registro de $2.651,7 \mathrm{~m}^{3}$, correspondendo a uma perda do volume comercial total colhido de $+3,15 \%$.

O resultado do inventário expedito registrou

TABELA 3: Resultados gerais das amostragens de resíduos (2010).

TABLE 3: General results of the residue sampling (2010).

\begin{tabular}{ccccc}
\hline \multirow{2}{*}{ Parcela } & Talhão & Sistema de & \multicolumn{2}{c}{ Volume de Resíduo m $^{3}$} \\
\cline { 4 - 5 } & & colheita & Parcela & Hectare \\
\hline R1 & 75 & Mecanizado & 1,06 & 53,12 \\
R2 & 42 & Mecanizado & 0,11 & 5,44 \\
R3 & 32 & Semimecanizado & 0,30 & 15,08 \\
R4 & 15 & Semimecanizado & 0,24 & 12,28 \\
R5 & 71 & Mecanizado & 1,05 & 52,61 \\
R6 & 94 & Mecanizado & 0,39 & 19,47 \\
R7 & 110 & Mecanizado & 1,62 & 81,11 \\
R8 & 103 & Mecanizado & 1,05 & 52,51 \\
R9 & 71 & Mecanizado & 1,93 & 96,42 \\
\hline
\end{tabular}


TABELA 4: Resultados gerais do inventário expedito de madeira colhida (2010).

TABLE 4: General results of the expedited inventory of timber harvested (2010).

\begin{tabular}{|c|c|c|c|c|c|}
\hline \multirow{2}{*}{ Classe diamétrica $(\mathrm{cm})$} & \multirow{2}{*}{ Comprimento (m) } & \multicolumn{2}{|c|}{ Madeira velha } & \multicolumn{2}{|c|}{ Madeira nova } \\
\hline & & Toras (un.) & Volume $\left(\mathrm{m}^{3}\right)$ & Toras (un.) & Volume $\left(\mathrm{m}^{3}\right)$ \\
\hline \multirow{3}{*}{8 a 18} & 2,4 & 832 & 776,92 & - & $3.400,00$ \\
\hline & $>2,4$ & 950 & 31,52 & - & - \\
\hline & $<2,4$ & 1.385 & 42,28 & - & - \\
\hline \multirow{2}{*}{18 a 23} & 1,9 & 451 & 604,47 & 500 & - \\
\hline & 2,65 & 1.076 & 296,95 & 517 & 645,22 \\
\hline \multirow{2}{*}{23 a 30} & 1 & 2.409 & 132,87 & 950 & 52,40 \\
\hline & 2,65 & 1.857 & 377,99 & 529 & 637,32 \\
\hline \multirow{2}{*}{30 a 40} & 1 & 2.243 & 215,80 & - & - \\
\hline & 2,65 & 420 & 137,84 & 220 & 306,09 \\
\hline \multirow{2}{*}{$>40$} & 1 & 279 & 35,06 & 1.202 & 151,05 \\
\hline & 2,65 & 275 & 251,32 & 436 & 145,19 \\
\hline Tota & & 12.177 & 2651,7 & 4.354 & $5.337,27$ \\
\hline
\end{tabular}

falhas no apontamento da produção, indicando um possível treinamento do funcionário designado a essa função, assim como dos operadores de colheita, na medida em que foram registrados desperdícios de madeiras que poderiam ser consideradas como comerciais.

\section{Expedição de Madeira (3)}

Para a verificação da área de expedição de madeira, foram auditados os volumes de madeira expedidos, a medição de toras individuais e a medição em metro estéreo de cargas. A empresa adota como padrão, os seguintes sortimentos comerciais e métodos de medição (Tabela 5).

Para os sortimentos medidos em metro estéreo, a empresa adota um único fator de conversão, o Fc 0,7. A auditoria em campo calculou os fatores de conversão de metro estéreo para metro cúbico, dos mesmos sortimentos considerados pela empresa na elaboração do $\mathrm{Fc} 0,7$, e encontrou um valor de Fc 0,64, o que revela a diferença entre as medições. Ainda, constata que a empresa se utiliza erroneamente de seus fatores de conversão, visto que, calcula um único $\mathrm{Fc}$ para uma grande abrangência diamétrica ( 8 a 29,99 cm) e compõe as cargas nos caminhões, separando-as por sortimentos.

No tocante a última classe, $\geq 30 \mathrm{~cm}$, a diferença deveu-se a falhas no método de cubicação de toras individuais aplicado pelos cubicadores (Figura 1).

A metodologia de cubicação utilizada pela empresa não segue um padrão reconhecido pela literatura, na medida em que o diâmetro da tora era coletado somente em uma medida (da ponta fina) e empregado o comprimento padrão indicado pela área comercial. Na realidade deveriam ser coletadas duas medidas perpendiculares de diâmetro nas duas pontas das toras (ponta fina e ponta grossa) e a medição do comprimento real da tora, o que orienta o método de cubicação Smalian (e adotado neste estudo).

Na classe diamétrica de 8 a $18 \mathrm{~cm}$ (pro-

TABELA 5: Sortimentos utilizados na empresa.

TABLE 5: Assortments used in the company.

\begin{tabular}{ccc}
\hline $\begin{array}{c}\text { Classe } \\
\text { diamétrica }(\mathrm{cm})\end{array}$ & $\begin{array}{c}\text { Comprimento } \\
\text { da tora }(\mathrm{m})\end{array}$ & $\begin{array}{c}\text { Método de } \\
\text { medição da } \\
\text { madeira }\end{array}$ \\
\hline$<8$ & 2,40 & Metro estéreo (st) \\
8 a 18 & 2,65 & Metro estéreo (st) \\
18 a 23 & 2,65 & Metro estéreo (st) \\
23 a 30 & 2,65 & Metro estéreo \\
$\geq 30$ & 2,65 & Metro cúbico \\
\hline
\end{tabular}




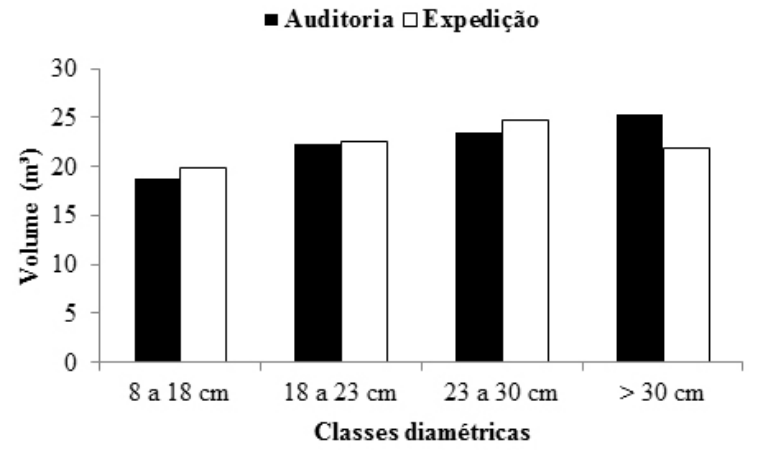

FIGURA 1: Comparação entre os volumes verificados de acordo com os sortimentos comerciais (2010).

FIGURE 1: Comparison between the volume scanned in accordance with the commercial assortments (2010).

cesso), onde o comprimento de toras deveria ser de $2,40 \mathrm{~m}$, sendo aceitável a variação entre 2,38 a $2,42 \mathrm{~m}$, a dispersão encontrada foi de $0,92 \mathrm{~m}$ a 2,82 $\mathrm{m}$. Para as classes diamétricas seguintes o comprimento das toras comerciais é de $2,65 \mathrm{~m}$, aceitando a variação entre 2,63 a $2,67 \mathrm{~m}$. No caso do sortimento 18 a $23 \mathrm{~cm}$, a variação encontrada foi de 2,62 a 2,81 m. Para 23 a $30 \mathrm{~cm}$, a variação foi de 2,63 a $2,85 \mathrm{~m}$, e para as toras $>30 \mathrm{~cm}$, a variação foi de 2,39 a 2,93 m (Figura 2).

Ainda, através da posse das medições de diâmetros, pode ser verificada a classificação das toras em suas classes diamétricas comerciais (Figura 3). Deve-se lembrar que os preços comercializados por $\mathrm{m}^{3}$ são diferentes para cada classe diamétrica,

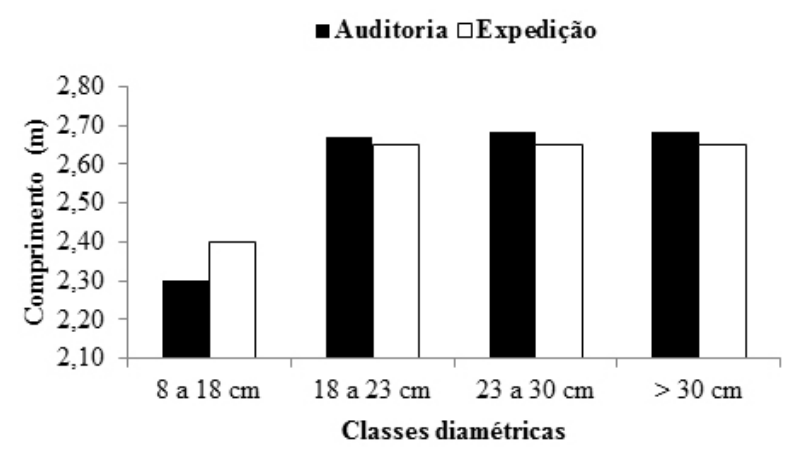

FIGURA 2: Comparação entre os comprimentos de toras medidos pela auditoria e pela expedição.

FIGURE 2: Comparison between the lengths of logs measured by verification and dispatch.
—Abaixo da classificação $\square$ Dentro da classificação $\square$ Acima da classificação

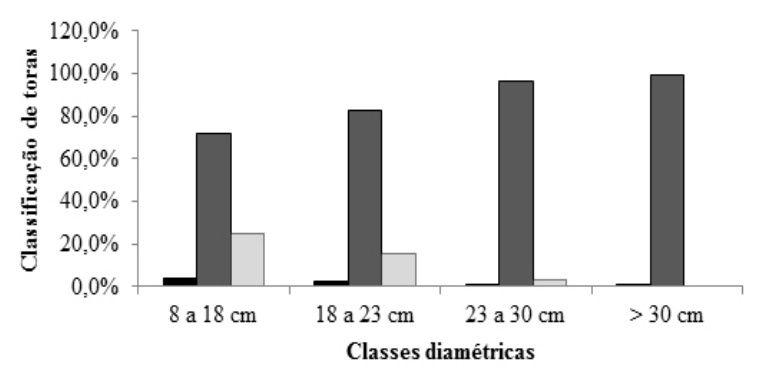

FIGURA 3: Comparação de desvios na medição de diâmetro nos sortimentos

FIGURE 3: Comparison of deviations in the measurement of diameter in the assortments

e, portanto, um erro de classificação do diâmetro das toras, influencia diretamente os resultados financeiros.

Dos desvios constatados nas classes diamétricas, a diferença mais significativa está na carga 8 a $18 \mathrm{~cm}$ (Figura 4).

Quando a madeira comercial (grossa) não atinge o comprimento desejado na venda que é de $2,65 \mathrm{~m}$, esta madeira é traçada em porções menores e vendida como madeira de processo, sendo repassada para a menor classe diamétrica (8 a18 $\mathrm{cm})$. Vale atentar que esta madeira de processo não é cubicada e sim apenas medida em metro estéreo e convertida $\mathrm{em}^{3}$ por um fator de conversão. Como neste caso existe a transferência de madeira grossa

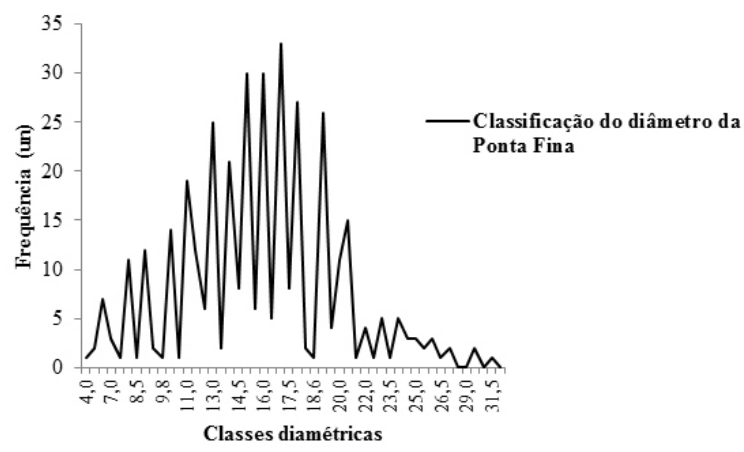

FIGURA 4: Composição de diâmetros da carga de 8 a18 cm.

FIGURE 4: Composition of charge diameters from 8 to $18 \mathrm{~cm}$. 
junto a madeira fina o fator de conversão deveria ser diferente do que a expedição utilizou $(0,60)$ que é somente destinado para a madeira fina com 8 a18 $\mathrm{cm}$ de diâmetro.

Em resumo, no tocante à expedição florestal, a auditoria na medição de madeira indicou grande dispersão, totalizando $-3,08 \%$ do volume total, conforme a soma dos sortimentos:

a) 8 a $18 \mathrm{~cm}$, com $2,40 \mathrm{~m}:+5,07 \%$;

b) 18 a $13 \mathrm{~cm}$, com 2,65 m: +0,79\%;

c) 23 a $30 \mathrm{~cm}$, com $2,65 \mathrm{~m}:+5,40 \%$; e

d) $\geq 30 \mathrm{~cm}$, com 2,65 m: - 13,51\%.

Do ponto de vista do inventário florestal, os percentuais encontrados representarão uma diferença dos volumes estimados por sortimento, o que de forma geral, resultará em um deficit total de madeira de $-3,08 \%$. Do ponto de vista financeiro, o percentual encontrado para o sortimento $\geq 30 \mathrm{~cm}(-13,51 \%)$ é interpretado de grande impacto financeiro, pois ele é o sortimento que agrega maior valor por $\mathrm{m}^{3}$.

Completando a última etapa do PDCA (Manutenção, A=agir), têm-se os seguintes resultados:

\section{CONCLUSÕES}

O Braisntorming e o PDCA mostraram-se ferramentas de grande aplicabilidade e eficiência no processo de controle entre o volume produzido (expedido + estoque + medição) e o estimado pelo inventário florestal, na medida em que criaram possibilidades de aperfeiçoamento dos procedimentos de gerenciamento operacional florestal. Estas ferramentas supriram as necessidades de informação ao planejamento florestal e favoreceram a garantia no fornecimento do produto com qualidade e satisfação do cliente.

A investigação identificou quais processos das atividades de inventário florestal, colheita florestal ou expedição de madeira, fizeram parte da contribuição do fato gerador de inconsistências de informações entre o volume de madeira estimado e o efetivamente colhido, inicialmente computado como $-24,73 \%$. Através da realização das verificações e auditorias nos processos de cada atividade previamente discutidos e definidos pelas ferramentas da qualidade, conclui-se que:

Inventário Florestal $(+13,84 \%)$ : teve como ponto fraco a cartografia, notadamente responsável por representar um acréscimo no volume total estimado de $+13,84 \%$. Esse dado mostra a importância de trabalhos cartográficos serem

TABELA 5: Etapa "Manutenção, A = agir" do PDCA.

TABLE 5: Stage "Maintenance, $A=$ action" PDCA.

ITENS

MANUTENÇÃO

$\mathrm{A}=$ Agir

\section{1 - INVENTÁRIO \\ FLORESTAL E \\ CARTOGRAFIA}

2 - COLHEITA FLORESTAL

3 - EXPEDIÇÃO DE MADEIRA
A área de inventário florestal deverá sistematicamente realizar o monitoramento das áreas inventariadas, através de auditorias de campo e certificar-se do processamento das informações;

Todas as fazendas programadas para a colheita deverão ter sua base cartográfica revisada e se possível atualizadas com o uso de fotos ou imagens áreas recentes. Esta checagem deverá ser realizada concomitantemente com a colheita florestal e corrigida se for necessária;

Deve haver um maior aproveitamento do material que atualmente vem sendo descartado para madeira de processo, diminuindo os resíduos em campo;

Deve haver um acompanhamento mais eficiente do levantamento de madeira produzida e estocada em campo;

A madeira não deve permanecer por muito tempo estocado, a fim de evitar possíveis manchas azuladas.

O método de cubicação deve ser monitorado através de auditorias mensais, a fim de garantir sua aplicabilidade. Os fatores de conversão devem ser adequados para o sortimento e específico para a floresta colhida. 
realizados com grande precisão;

Colheita Florestal $(+15,62 \%)$ : os resíduos lenhosos remanescentes da operação de colheita florestal foram responsáveis por $+6,68 \%$ do volume total estimado para o empreendimento, $\mathrm{O}$ apontamento do estoque da produção foi responsável pelos restantes $+8,94 \%$, sendo divididos em madeira nova $(+5,79)$ e madeira velha $(+3,15)$;

Expedição de madeira $(-3,08 \%)$ : em todos os sortimentos praticados pela empresa, foram detectados pelas auditorias divergências dos dados. Sortimento de 8 a $18 \mathrm{~cm}$, com $2,40 \mathrm{~m}$ : $+5,07 \%$; 18 a $13 \mathrm{~cm}$, com 2,65 m: $+0,79 \%$; 23 a $30 \mathrm{~cm}$, com $2,65 \mathrm{~m}:+5,40 \%$ e $\geq 30 \mathrm{~cm}$, com 2,65 m: $-13,51 \%$.

Desta forma, somando os percentuais calculados para cada atividade, tem-se o valor de $+26,38 \%$. Deduzindo este valor do percentual do erro inicial $(-24,73 \%)$, tem-se um saldo de $+1,65 \%$. Portanto, infere-se que as inconsistências de informações, entre o volume estimado pelo inventário florestal e o efetivamente colhido, foram totalmente identificadas nesta investigação.

Assim, as ferramentas Braisntorming e PDCA apontaram falhas no gerenciamento operacional florestal do empreendimento analisado e recomendaram a implantação de algumas rotinas de acompanhamento e de checagem de cada uma das atividades envolvidas neste gerenciamento.

\section{REFERÊNCIAS BIBLIOGRÁFICAS}

ARCE, J. E. Um sistema de programação do transporte principal de multiprodutos florestais visando a minimização de custos. 1997. $111 \mathrm{f}$. Dissertação (Mestrado em Ciências Florestais) Universidade Federal do Paraná, Curitiba, 1997.

ARCE, J. E. Um sistema de análise, simulação e otimização do sortimento florestal em função da demanda por multiprodutos e dos custos de transporte. 2000. $136 \mathrm{f}$. Tese (Doutorado em
Ciências Florestais) - Universidade Federal do Paraná, Curitiba, 2000.

BONDUELLE, G. Qualidade total na gestão florestal. Material didático do curso de especialização à distância em gestão florestal. Universidade Federal do Paraná, PECCA, Curitiba, 2007. 205 p.

COLETTI, J. et. al. Avaliação de defeitos no processo de fabricação de lamelas para pisos de madeira engenheira dos com uso de ferramentas de controle de qualidade. Acta Amazonica, v. 40, n. 1, p. $135-140,2010$.

EQUIPE GRIFO. Aplicando 5S na gestão da qualidade total. São Paulo: Pioneira, 1998.

FOELKEL, C. Gestão ecoeficiente dos resíduos florestais lenhosos da eucaliptocultura. 2007. EucalyptusOnLine Book. Disponível em: $<\mathrm{http}: / /$ www.eucalyptus.com.br/capitulos/PT0 7 residuoslenhosos.pdf $>$ Acesso em: 17/08/2012.

JURAN, J. M.; GRYNA, F. M. Controle de qualidade. São Paulo: Makron Books, 1991.360 p. JURAN, J. M. Juran on planning for quality. New York: The Free Press, 1998.

LEITE, H. G., ANDRADE, V. C. L. de. Um método para condução de inventários florestais sem o uso de equações volumétricas. Revista Árvore, ViçosaMG, v. 26, p. 321-328, 2002.

LEITE, H. G. et. al. Importância das variáveis altura dominante e altura total em equações hipsométricas e volumétricas. Revista Árvore, Viçosa-MG, v. 27, n. 3, p. 301-310, 2003.

MIGUEL, E. P. Avaliação biométrica e prognose da produção de Eucalyptusurophylla (s. t. Blake) na região norte do estado de Goiás. 2009. 165 f. Dissertação (Mestrado em Engenharia Florestal) Universidade Federal do Paraná, Curitiba, 2009.

PACHECO, A. P. R. et al. O Ciclo PDCA na Gestão do Conhecimento: uma abordagem sistêmica. Disponível em: < http://www.isssbrasil.usp.br/ pdfs2/ana.pdf $>$. Acesso em: 03/06/2011. 